\title{
The Organizational Performance Dimensions on Achieving Organizational Goals: A Case Study of the Minister's Office of Dhofar State, Oman
}

\author{
Khalid Ghanim Mohammed Alkathiri*, Mohamed Mihlar \\ Faculty of Leadership and Management, Islamic Science University of Malaysia (USIM), Negeri Sembilan, \\ Malaysia \\ * alhazar2020@ hotmail.com
}

\begin{abstract}
KEYWORDS: $\quad$ Organizational Performance, Organizational Tasks, Roles, Achievement of Goals.
\end{abstract}
\begin{abstract}
:
This descriptive article discusses the dimensions of the efficiency of organizational performance in achieving organizational goals, which is part of an expanded message conducted by the researcher entitled: The effect of organizational culture as a variable affecting the relationship between leadership patterns and organizational performance: a case study in the office of the Minister of State and the Dhofar Governor in the Sultanate of Oman. The problem lies, in the presence of obstacles and challenges facing the leadership role of managers in Omani institutions, and the presence of a weakness in the administrative and financial public performance, resulting in a clear weakness in the performance of service institutions and the Omani public sector. Therefore, the study aims to discuss the dimensions of the efficiency of organizational performance, which includes organizational tasks, roles, and achievement of goals. The researcher adopted the descriptive analytical method, the study consisted of three topics, the first for organizational tasks, and the second for roles, while the third topic discussed achieving goals. The results indicated that the institutions suffer from great financial problems due to the global financial crisis, and the institutions are exposed to many external and internal influences that affect the nature of human resource management practices and their role in the organization. It can only exercise an advisory role in a limited scope and to the extent permitted by regulations and laws in organizations. The human resources management suffers from deliberate marginalization permanently, as working in government institutions is typical work without creativity, and therefore it is difficult to identify the direction of roles, especially if the employee is working hard to complete the work.
\end{abstract}


أبعاد كفاءة الأداء التنظيمي في تحقيق الأهداف المنظمة: دراسة حالة مكتب وزير الدولة بمحافظة ظفار بسلطنة عمان

\author{
خالد غانم محمد الكثيري*، د. محمد مهلار \\ كلية القيادة والإدارة، جامعة العلوم الإسلامية الماليزية، نكري سيمبيلان، ماليزيا \\ *alhazar2020@ hotmail.com
}

الكلمات المفتاحية | الأداء التنظيمي، المهام التنظيمية، الأدوار، تحقيق الأهداف.

Crossref doi https://doi.org/10.51345/.v32i3.449.g235

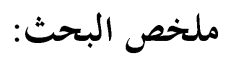
تناقش هذه المقالة الوصفية؛ أبعاد كفاءة الأداء التنظيمي في تحقيق الأهداف المنظمية، وهي جزء من رسالة موسعة يجريها الباحث

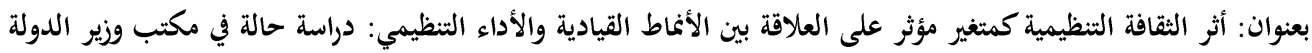

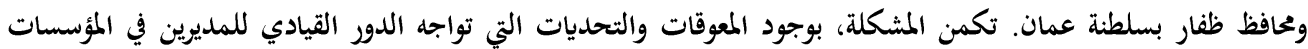

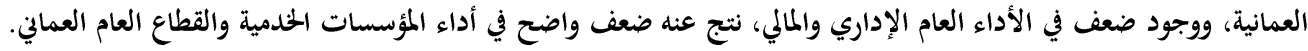

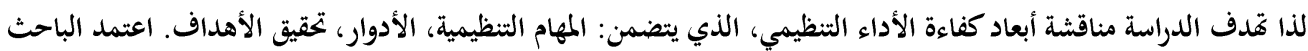

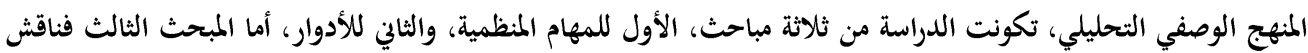

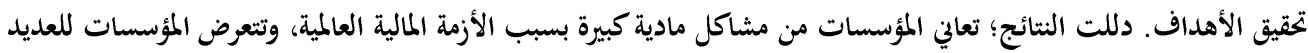

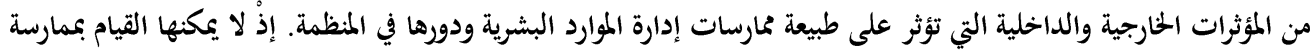

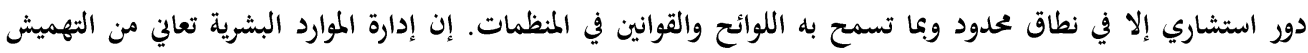

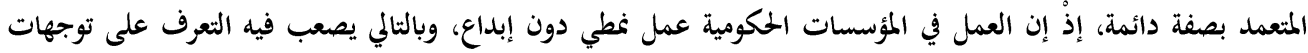
الأدوار خاصة إذا كان الموظف يجتهد بشده للإنجاز الأعمال.

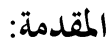

يعد الأداء التنظيمي من أهم المفاهيم التي نالت اهتمام الباحثين والدارسين في جميع الججالات، لما يكمن وراء أهميته للفرد والمنظمة على حد سواء، لأن المنظمات تحقق أهدافها ورؤيتها من خلال كفاءة الأداء التنظيمي فيها(1)، من هنا كان كفاءة الأداء التنظيمي بمفهومه البسيط عبارة عن قيام الأفراد بالأعمال

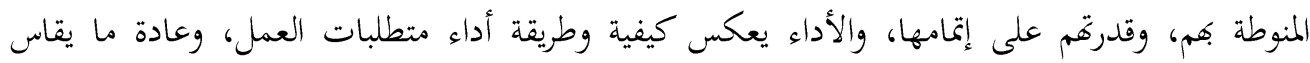

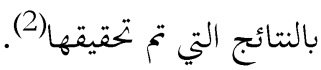


ويعرف الأداء على أنه: "النتيجة المتحصل عليها في أي ميدان عمل، كالنتائج التي تم تحقيقها لدى ممارسة

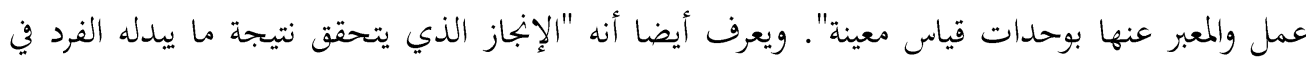

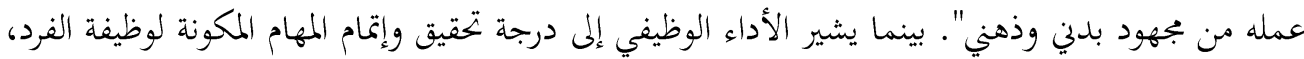

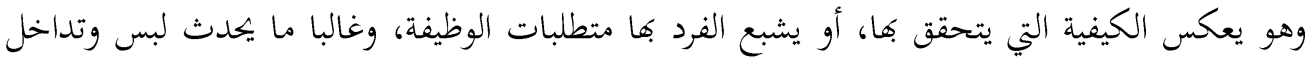

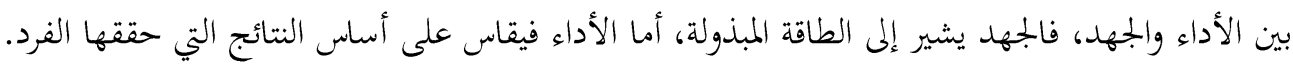
ويعبر مفهوم الأداء الوظيفي عن "الأثر الصافي لجهود الفرد التي تبدأ بالقدرات وإدراك الدور أو المهام والذي الذي إني

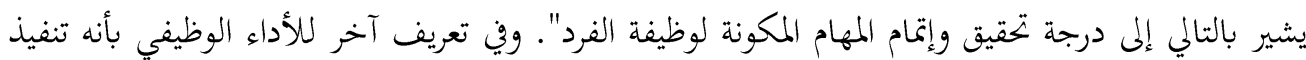
الموظف لأعماله ومسئولياته التي تكلفه بها المنظمة أو الجهة التي ترتبط وظيفته بها. وقد عرف عبيد، (2009) كفاءة الأداء التنظيمي بأنه مجموع النتائج التي حققها الفرد نتيجة الجها المبذول، وإتباعه لأنظمة وتعليمات المنظمة التي يعمل بها ويسعى لتحقيق أهدافها. وعرف (المالكي،

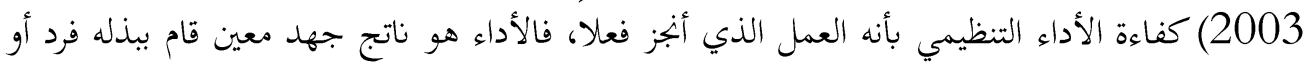
منظمة لإنجاز عمل معين وفقا للمعدل المطلوب من الموظف أو الإدارة ذات الكفاية والتدريب.

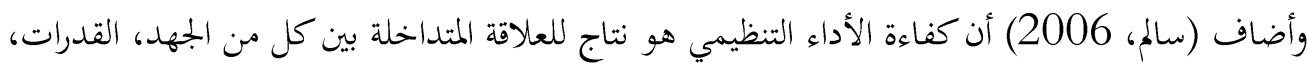

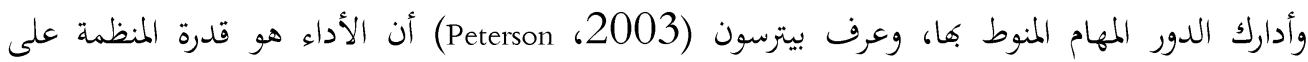
استخدام مواردها بكفاءة وفاعلية، وإنتاج مخرجات متناغمة ومتجانسة مع أهدافها ومناسبة لمستخدميها، وعرف كفاءة الأداء التنيمي ويلن و هونجر (Wheelen \& Hunger 2002) أن هو النتيجة النهائية للنشاط، ويرى الباحث أن أداء العاملين هو السلوك المبذول من الفرد في العمل، حيث يقيس الأداء التنظيمي دور العاملين في المنظمة وبجهودات الأعمال. ويرى ويلن وهونجر (2002) أن كفاءة الأداء التنظيمي هو النتيجة النهائية للنشاط إلا أفم لم يوضحوا

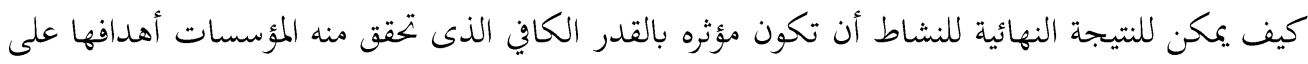

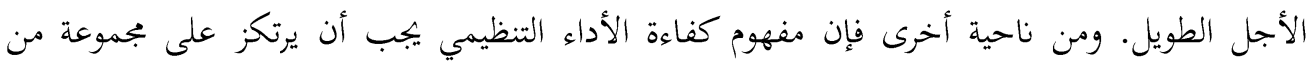

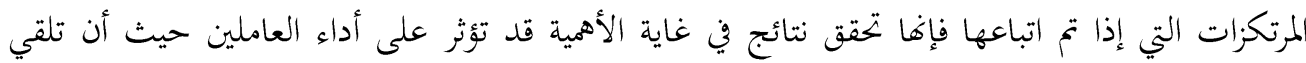
العاملين على مستوى من التدريب الرفيع بالإضافة إلى حصولم على مستحقاقم من الحوافز والتعويضات، وقد يؤدي إلى تحسن الأداء فضلا عن حصول العاملين على نصيبهم من الرعاية الطبية والرعاية التعليمية، وقد يدفع العاملين إلى تحقيق مزيد من التقدم في أدائهم الوظيفي بشكل ملفت، فمفهوم الأداء يمكن أن يحقق ما تصبو إليه المؤسسات إذا ما تم مراعاة تلك العناصر. 


\section{مشكلة الدراسة:}

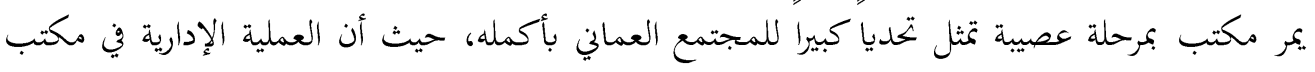
وزير الدولة بمحافظة ظفار بسلطنة عمان تعاني من غياب التنسيق بشكل كبير في العمل التنظيمي، وتعاني معظم المؤسسات العمانية من أزمات إدارية واقتصادية نتيجة تقلبات أسعار النفط (3). رأت الدراسات التي عنيت بأداء الموظفين في سلطنة عمان، منها دراسة مسن (2018) بأن الأداء العام في المؤسسات العمانية يعاني كغيره من المؤسسات الأخرى، في ضوء غياب التشخيص الصحيح للمشاكل الإدارية القائمة للأسس العلمية التي بموجبها يتم اختيار الأفراد وتعيينهم بالوظائف القيادية وغير القيادية

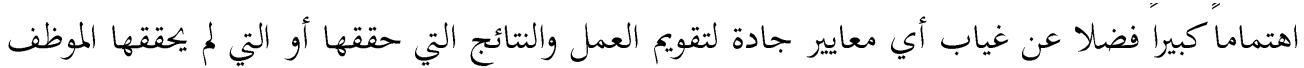
أو المدير الحالي بالمجتمع العماني. وقد أكدت دراسة الغساني (2006) المعوقات والتحديات التي تواجه الدور القيادي للمديرين في

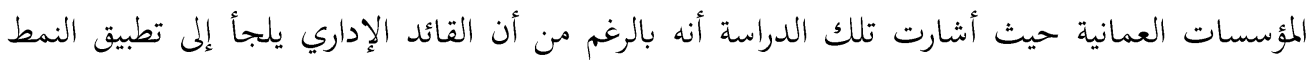
التسلطي إلا أن هذا النمط قد أدى إلى استقرار المؤسسات. أما دراسة (العكاري، 2014) فقد فئد رأت بأن

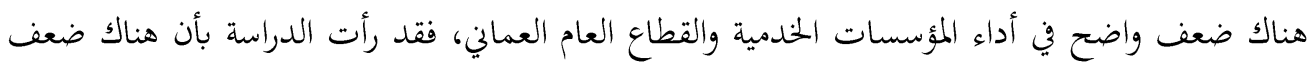
في الأداء العام الإداري والمالي وضعف أداء العناصر الإدارية والمالية مما أدى إلى تفشي البيروقراطية والترهل

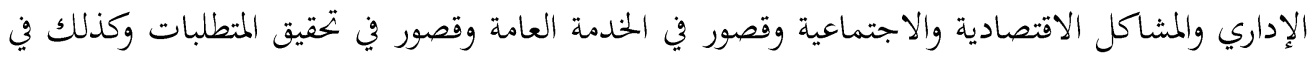

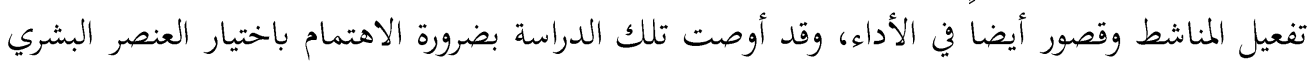
وفقا للمعايير الدقيقة التي يجب أن توضع بدقة متناهية، وتدريب وتأهيل العناصر المعينة ومعالجة الموارد البشرية على كافة الأوجه والأصعدة. كما أن تقرير خطة عمان (2040) قد أشار إلى التحاه الدولة إلى محاولة رفع كفاءة القيادات الإدارية في كافة المؤسسات العمانية كما تسعي إلى تطوير اللوائح والقوانين العاملة في كافة المؤسسات العمانية. لذاء

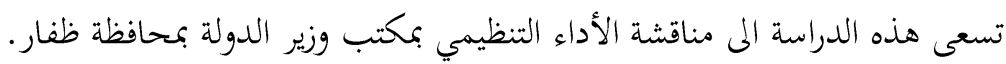

\section{أهداف الدراسة}

تسعى هذه الدراسة إلى تحقيق الهدف الرئيس المتمثل في مناقشة أبعاد كفاءة الأداء التنظيمي، الذي يتضمن:

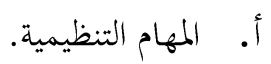




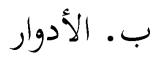 ت. تحقيق الأهداف}

\section{الدراسات السابقة:}

دراسة أبوبكر المازوغي، 2019، أثر قيادة الموارد البشرية في تحسين الأداء التنظيمي: الثقافة التنظيمية كمتغير وسيط دراسة حالة شركة الخدمات العامة فرع طرابلس، رسالة دكتوراة غير منشورة، كلية الإدارة جامعة شاة علم، ماليزيا. تهدف الدراسة إلى التعرف على أثر قيادة الموارد البشرية في تحسين الأداء التنظيمي: الثقافة التنظيمية كمتغير وسيط دراسة حالة شركة الخدمات العامة فرع طرابلس، ولقد اتبعت الدراسة المنهج الوصفي التحليلي لوصف وتحليل أثر قيادة الموارد البشرية في تحسين الأداء التنظيمي: الثقافة التنظيمية كمتغير وسيط دراسة ولته حالة شركة الحدمات العامة فرع طرابلس، وكانت عينة الدراسة 217 من العاملين في شركة الخدمات العامة العادية فرع طرابلس، ولقد توصل الباحث إلى العديد من النتائج من بينها أن العدالة التنظيمية لها دور إيجابي في

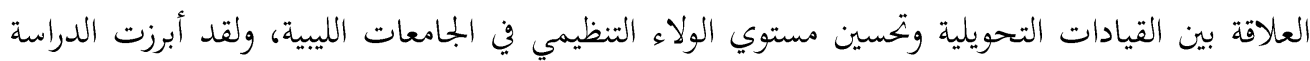
ضرورة التوسع في التعرف على تأثير القيادات التحويلية على العدالة الإجرائية كأحد أبرز المتغيرات الوسيطة التي يمكن من خلالها التعرف على مدى تأثيرها على تحسين مستوى الولاء التنظيمي في الجامعات الليبية من وجهة نظر أعضاء هيئة التدريس. دراسة أبو القاسم على حسن أبوسوار، 2019، أثر التخطيط الإستراتيجي على الأداء المؤسسي الثقافة التنظيمية كمتغير وسيط، دراسة تطبيقية على شركة أوتوباثى المحدودة للسيارات.

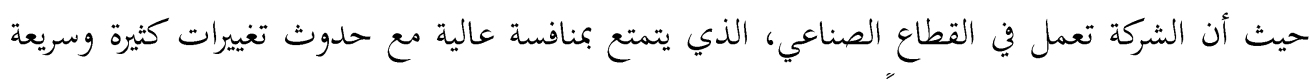
للغاية في البيئة المخيطة ، كان لزاما على الشركة الاستجابة لها من خلال تبني التخطيط الاستراتيجي .لذا لـاس حاولت هذه الدراسة معرفة أثر التخطيط الاستراتيجي على الأداء المؤسسي ومعرفة أثر الثقافة التنظيمية في

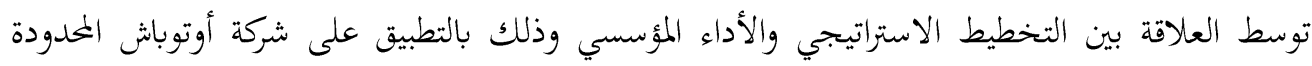

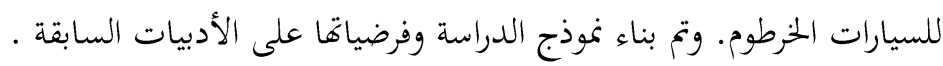

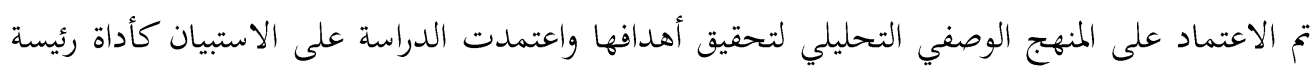
في جمع البيانات الأولية من أفراد بجتمع الدراسة عن طريق أسلوب الحصر الشامل البالغ عددهم (130) 
وتم استرجاع (118) استبيان تمثل (90.8\%) من مجتمع الدراسة ، كما تم استخدام برنامج (SPSS) في معالجة وتحليل البيانات واختبار صحة الفروض. أظهرت نتائج الدراسة وجود علاقة إيبابية بين التخطيط الاستراتيجي والأداء المؤسسي كما اتضح وجود

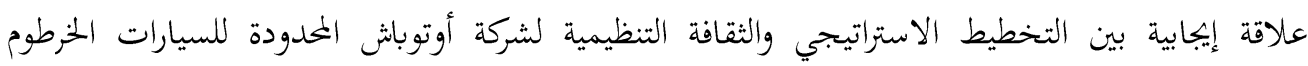

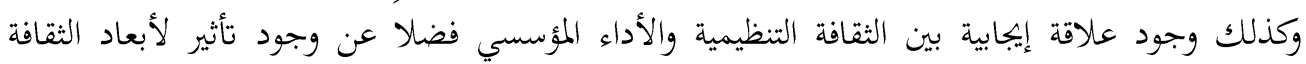
التنظيمية (القيم التنظيمية، التوقعات التنظيمية) تتوسط العلاقة بين التخطيط الاستراتيجي والأداء المؤسسي. وبناء على تلك النتائج تم تقديم عدد من التوصيات أهمها زيادة الاهتمام بالتخطيط الاستراتيجي ومشاركة العاملين في وضع الأهداف الإستراتيجية و الاهتمام أكثر بتحليل البيئة الخارجية لمعرفة التهديدات وبتحنبها

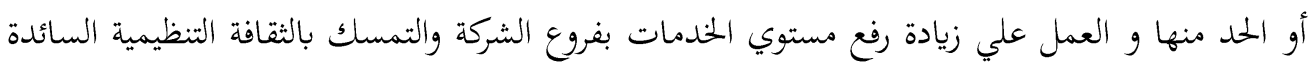
وتقويتها بالشركة

دراسة ألمم، 2014، دور القيادة التحويلية في تحسين الأداء الإداري لمديري مدارس التعليم الأساسي بجمهورية مصر. هدفت الدراسة إلى التعرف على تحديد مفهوم القيادة التحويلية وعناصر القيادة التحويلية التربوية وكذلك كشف واقع ممارسة مديري مدارس الحلقة الأولي من التعليم الأساسي لأسلوب القيادة التحويلية بالإضافة

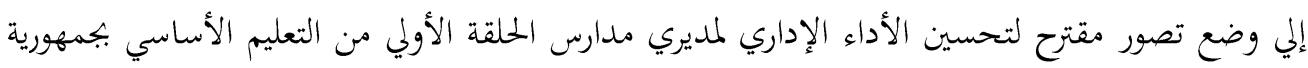
مصر العربية، ولقد اتبعت الدراسة المنهج الوصفي التحليلي لوصف وتحليل عينة الدراسة من أعضا هيئة التدريس بمجموعة من المدارس في القاهرة والإسكندرية والجيزة، ولقد توصلت الدراسة إلى العديد من النتائج من بينها أن المديرين يمارسون القيادة التحويلية بدرجة متوسطة ووجود فروق ذات دلالة إحصائية بين استجابات المديرين والمعلمين لصالح المديرين. وأوصت الدراسة إلى أهمية تنمية وعي القيادات الإدارية العليا بالوزارة والإدارات التعليمية بالحاجة إلى التغيير. دراسة أحمد فوج الله، 2016، دور الثقافة التنظيمية كمتغير معدل في العلاقة بين رأس المال الفكري وتطوير الأداء: دراسة ميدانية على الجامعات الفلسطينية العاملة في قطاع غزة. تهدف الدراسة إلى التعرف على دور الثقافة التنظيمية كمتغير معدل في العلاقة بين رأس المال الفكري

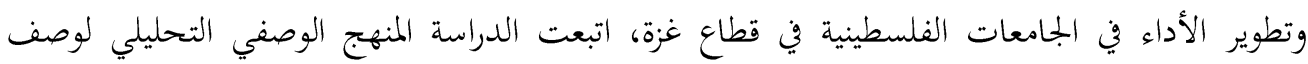
وتحليل دور الثقافة التنظيمية كمتغير معدل في العلاقة بين رأس المال الفكري وتطوير الأداء في الجامعات الفلسطينية في قطاع غزة، وتكمن مشكلة الدراسة في عدم وضوح دور الثقافة التنظيمية في تطوير الأداء. 
ولقد استخدمت الدراسة خمس جامعات فلسطينية وبالتحديد عدد 261 من العاملين في الجامعات الفلسطينية، ولقد توصل الباحث إلى العديد من النتائج من بينها أن الثقافة التنظيمية لها دور إيجابي في العلاقة بين رأس المال الفكري وتطوير الأداء. ولقد أوصت الدراسة بضرورة التوسع في التعرف على تأثير الثقافة التنظيمية في العلاقة بين القيادة التحويلية والأداء التنظيمي.

\section{منهجية الدراسة:}

لأجل تحقيق أهداف الدراسة، اعتمد الباحث المنهج الوصفي التحليلي، الذي يعتبر الأنسب بمثل هذه

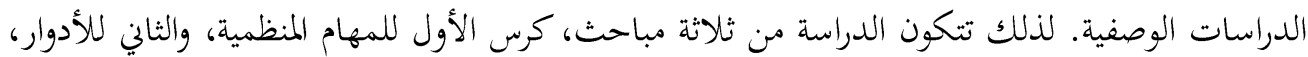
أما المبحث الثالث فناقش تحقيق الأهداف. ومن الجلدير بالذكر، أنَّ هناك أبعاد يختلفة للأداء تختلف باختلاف وجهات نظر الباحثين، لكنها يمكن أن تتفق في أمور متعددة، فهذه الأبعاد تحدد الاتحاه للأداء والمسار المراد له تحقيقه في المنظمة، ومن خلال الاطلاع على الأدب النظري، تم تحديد ثلاثة أبعاد في الدراسة الحالية وهي (المهام، والأدوار، تحقيق الأهداف). (الافن.

\section{المبحث الأول: المهام المنظيمية}

يتمثل تحليل المهام الوظيفية في تلك العملية التي يتم استخدامها في تحديد ووصف محتوى (مضمون)

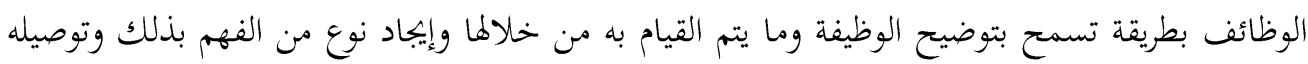

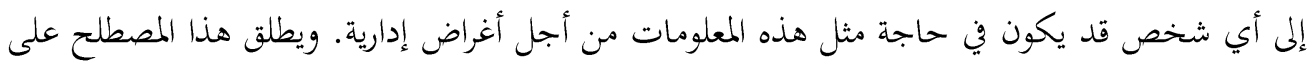

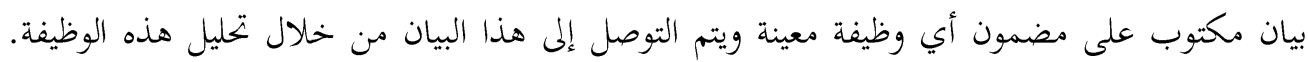

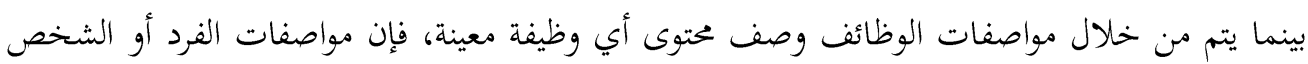
تصف السمات المطلوب توافرها في الشخص حتى يتمكن من القيام بالعمل الذي تم وصفه بمستوى معين يرضي صاحب العمل. هناك كثير من الأسباب التي تؤدي إلى تحليل المهام الوظيفية، وتتمثل المهام الرئيسية الخاصة بالمؤسسة فيما يأتي:

\section{أولاً: المهام الاختصاصية:}

وهي الممارسات التي تقوم بها الموارد البشرية في الشركات التابعة للقطاع الحكومي، أو تلك التابعة للقطاع الخاص، مثل التوظيف وتخطيط الموارد البشرية وتحليل وتقييم الوظائف، وبالرغم من أن العزاوي وجواد لهمباد

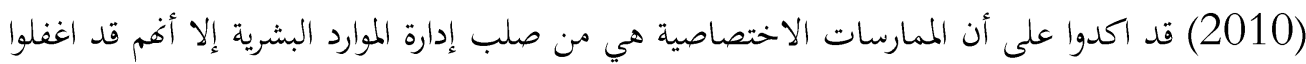


أن بعض الشركات والمنظمات الحديثة قد خلطوا بين ممارسات إدارة الموارد البشرية وبين إدارة شئون الأفراد أو المهام الوظيفية لإدارة شؤون الموظفين الأمر الذى يلزم معه تحديد الأنماط الوظيفية التي يمكن من خلالما تحديد الاختصاصات، والتعرف بدقة على الأماكن الشاغرة والتخطيط لإدارة الموارد البشرية بشكل سليم. ومن الملاحظ، أن العزاوي وجواد (2010) لم يوضحا طبيعة الممارسات الاختصاصية التي يمكن من خلالما أن تمارس إدارة الموارد البشرية أعمالها بسهولة، فالممارسات الاختصاصية للمؤسسات الصناعية تختلف عن الممارسات الاختصاصية للشركات الخدمية والشركات التجارية وكذلك فإن الممارسات الاختصاصية لشركات القطاع العام تختلف بشكل كبير عن الممارسات الاختصاصية لشركات القطاع الخاص، ومن خلال الممارسات الاختصاصية قد تظهر العديد من التصنيفات الأخرى لممارسات الموارد البشرية التي يمكن الاعتماد عليها في تغيير مسار إستراتيجية الموارد البشرية وتحقيق أهداف المنظمة بشكل طبيعي. وبناء على ما تقدم فإن الممارسات الاختصاصية التي تقوم بها الموارد البشرية يمكن من خلالها أيضاً التفريق بين المهام الموكلة لإدارة الموارد البشرية في القطاع العام والتي تختلف بشكل جذري عن المهام الوظيفية لتلك الإدارة في القطاع الخاص، فإدارة الموارد البشرية في القطاع العام والقطاع الحكومي يمكن من خلالما التعرف على القواعد والمعايير المطبقة في معظم المؤسسات الحكومية مع وجود اختلافات طفيفة في طرق وبالات العمل. أما الممارسات الاختصاصية في القطاع الخاص فيمكن من خلالما التعرف على مدى سيطرة أصحاب رأس المال على القرار الإداري في المؤسسة ومدى تدخلهم في الممارسات الاختصاصية لإدارة الموارد البشرية.

\section{ثانيا: المهام الإدارية:}

وهي تلك الممارسات المتعلقة بوظائف وأعمال الموارد البشرية، مثل التدريب والحوافز، وبالرغم من أن العزاوي وجواد (2010) قد أشاروا إلى أهمية وجود الممارسات الإدارية إلا أن اغفلوا أن تلك الممارسات الإدارية قد لا تكون موجودة على أرض الواقع أو بعبارة أخرى فقد لا تكون مطبقة في المؤسسات العامة أو المؤسسات الخاصة، وحيث أن معظم الشركات والمؤسسات تفضل استقطاب العمالة المدربة عن القيام بالبحث عن الاحتياجات التدريبية. وكذلك فإن العديد من المؤسسات غالبا تعاني من مشاكل مادية كبيرة وخاصة بعد أحداث الأزمة المالية العالمية محا يدفع أغلب الشركات إلى التعاقد مع العاملين المدربين ذوى الخبرة والمهارة في كافة المجالات، وبالرغم من أن الباحث يميل إلى قيام المؤسسات بالبرامج التدريبية المختلفة للعاملين فيها إلا أن هذا قد يدفع الشركات المنافسة للتعاقد مع العاملين بأجور أعلى الأمر الذى يؤكد أن التدريب يمكن التخلي عنه 
كممارسة إدارية للموارد البشرية، ومن جهة أخرى فإن العزاوي وجواد (2010) لم يوضحوا إلى أي مدى يمكن لإدارة الموارد البشرية أن تمارس دورها في تحديد الحوافز، وحيث أن معظم المؤسسات والشركات

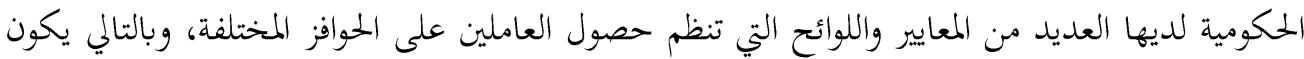
دور إدارة الموارد البشرية تنفيذ اللوائح فقط.

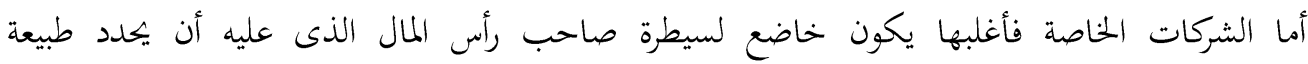

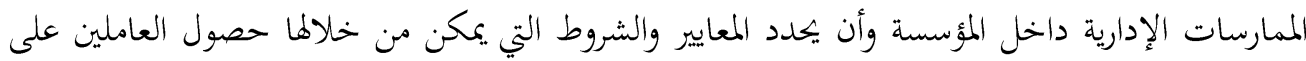
الحوافز مع الأخذ في الاعتبار أن مؤسسات القطاع الخاص يقوم صاحب المؤسسة أو الشركاء بوضع المعايير وضبط الممارسات الإدارية في المؤسسة وبالتالي لا يكون هناك فرصة للعاملين في إدارة الموارد البشرية لإحداث أي نوع من التغيير في الممارسات الإدارية.

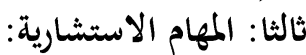

وهي تلك الممارسات المتعلقة بتقديم النصح، والمشورة للعاملين في المنظمة في النواحي الفنية والقانونية وتطوير التعليمات، والأنظمة المتعلقة بشؤون العاملين، مثل أنظمة ظروف العمل والحوافز والمخدمات المقدمة لهم وغيرها، وأختلف العديد من الباحثين في تحديد ما إذا كانت إدارة الموارد البشرية تقوم بالممارسات

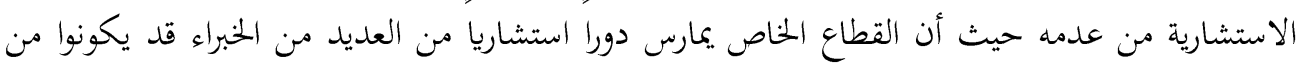
خارج المؤسسة أما القطاع العام أو الحكومي، ويقوم على أساس فكرة اتباع اللوائح والقوانين والمعايير الواجب توافرها، ومن الجدير بالذكر أن العزاوي وجواد (2010) قد اغفلوا أن الممارسات الاستشارية في الأغلب لا يمارسها إلا مستوى مديري العموم وبالتالي لا يكون للموظفين أي مساهمة تذكر حيث تختزل القيادات أي إنجازات إدارية أو استشارية بأسمائهم. وبالرغم من أن العزاوي وجواد (2010) قد أوضح أن الممارسات الاستشارية يمكن أن تمارس من خلال

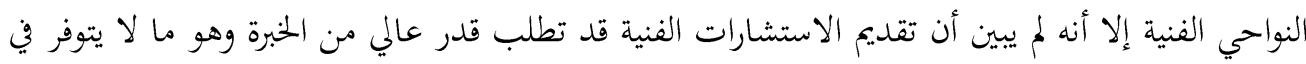

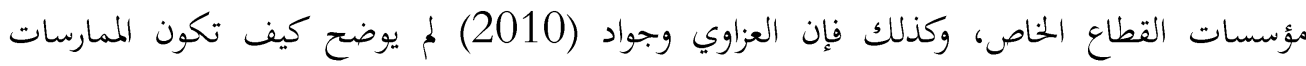

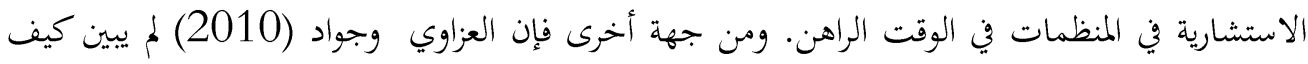
يمكن تقديم المشورة القانونية في ظل وجود إدارة تمارس الشئون القانونية مما قد يؤدى إلى تداخل المهام الوظيفية بين الإدارات داخل المؤسسة. ويطلق عليها بجموعة من المفكرين الإداريين مسمى وظائف إدارة الموارد البشرية، وهي بجموعة الأنشطة التي

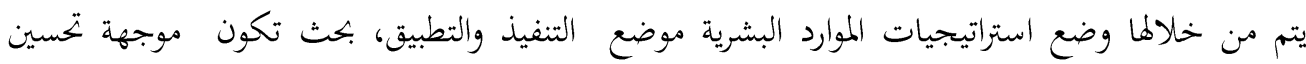


الأداء، وتعزيز جدارة الموارد البشرية ومهارتحا ومعرفتها من أجل تحقيق الاستراتيجي كما أشارا هينيمان وميلانوسكي ( Heneman \& Milanowski, 2011 )، وقد أشار أرمسترونغ (Armstrong, 2006) أن ممارسات إدارة الموارد البشرية هي التي هتم بتطوير استراتيجيات الموارد البشرية والسياسات والممارسات التي تؤثر في جميع جوانب الموارد البشرية، والمديرين المسؤولين عن العمل. وبين برناردان (Bernardin,2007) أن ممارسات

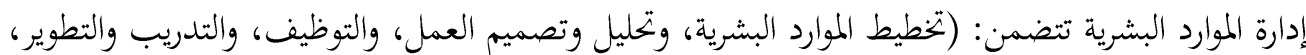

$$
\text { والتعويضات والمنافع، وتقييم الأداء). }
$$

وبالرغم من أن (Heneman \& Milanowski, 2011) قد أشارا أن وظائف إدارة الموارد البشرية من شأها أن

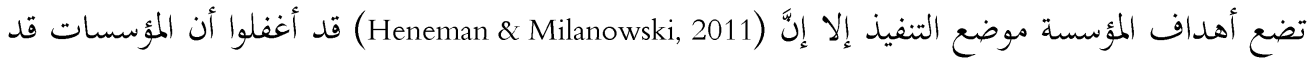
تتعرض للعديد من المؤثرات الخارجية والداخلية الأمر الذى قد يؤثر بشكل سلبي على تعاطي تلك إلك المؤسسات لتحقيق أهداف الموارد البشرية وكذلك تؤثر بشكل كبير على طبيعة ممارسات إدارة الموارد البشرية

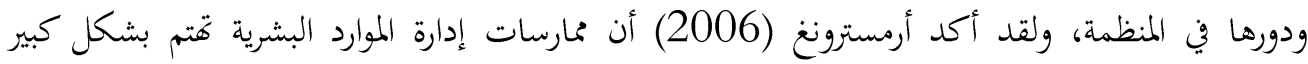
بالسياسات التي تؤثر في تحقيق أهداف الموارد البشرية إلا إنَّ أرمسترونغ (2006) لم يوضح بشكل مبأ مباشر

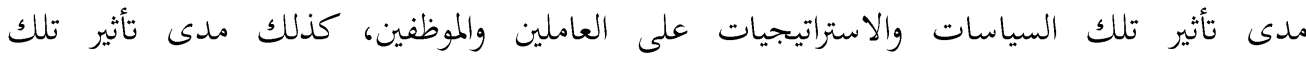
الاستراتيجيات على قدرة إدارة الموارد البشرية في ممارسة دورها الوظيفي. وبالرغم من أن برناردان (2007) قد أوضح أن ممارسات إدارة الموارد البشرية تتضمن تخطيط الموارد البشرية

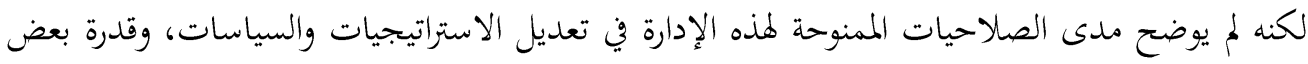
المؤسسات على تحليل وتصميم العمل، والسماح لهم بممارسة التوظيف، والتدريب والتطوير، والتعويضات والمنافع، وتقييم الأداء، وفي الواقع، فإن إدارة الموارد البشرية في الوقت الراهن لا يمكنها أن تقوم بممارسة دورا استشاريا إلا على نطاق محدود وبما تسمح به اللوائح والقوانين في المنظمات الحكومية أو شركات القطاع

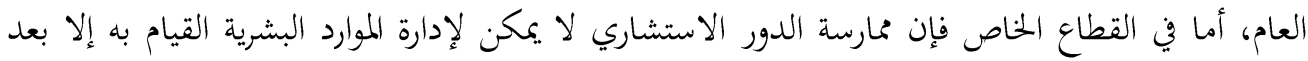
موافقة مجلس إدارة المؤسسة في القطاع الخاص. وكذلك فإن إدارة الموارد البشرية في المؤسسات الحكومية تعاني من التهميش المتعمد بصفة دائمة حيث

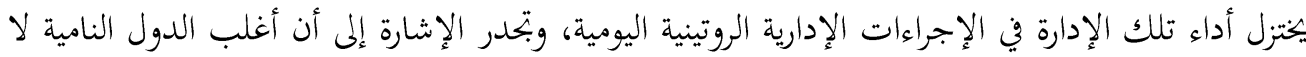
تعطى أهمية قصوى لإدارة الموارد البشرية وخاصة لدورها الاستشاري حيث يقع على عبئ هذه الإدارة مهمة تنفيذ الأوامر الإدارية بشكل كامل وسريع حيث تلتزم إدارة الموارد البشرية بتنفيذ اللوائح والقوانين وتطبيق الخصومات والحوافز طبقا للوائح المقررة ومتابعة إجراءات الحضور والانصراف والغياب وتسجيل العاملين في 
الإجازات المرضية، ويمكن أيضا لإدارة الموارد البشرية أن توضح احتياجات العمالة في كافة الإدارات والتخصصات المطلوبة وحصرها ورفع تقاريرها للإدارة العليا والتعامل مع الموظفين عبر المستندات الموثقة والمعتمدة. يؤيد الباحث كل ما ذكر سابقا ويضيف أن مارسات إدارة الموارد البشرية هي كيفية استخدام الإجراءات والطرق والأساليب الإدارية والفنية والعملية للإدارة الموارد البشرية، في التعامل مع العناصر البشرية في المنظمات، وكيف توجيها والاستفادة من كل الطاقات الكامنة لديها لتحقيق الأهداف المطلوبة في المنظمات.

المبحث الثالي: الأدوار: أشار الدحلة (2001) أن هناك العديد من الأبعاد التي يمكن الأخذ بها في استعراض أداء العاملين ومن بين أبرز تلك العوامل التي تؤثر في الأداء الأدوار. إلا إنَّ الدحلة لم يشير إلى مفهوم الأدوار حيث تعني المهام التي يتطلب من العاملين القيام بها في المؤسسات، وأن هذه الأدوار هي الأساس التي يتقاضون عليه أجورهم، ومن الجمير بالذكر أن المهام تختلف من مؤسسة لأخرى والمهام ذات طبيعة مختلفة فهناك العديد من العاملين ما يقومون بمهام الموظف والمدير في وقت واحد، كما أن الدحلة (2001) قد أشار إلى أن نتيجة الأدوار أن يعرف الموظفون النتائج المتوقعة لكل منهم، إلا إنَّ الدحلة (2001) أغفل أن هناك العديد من المؤسسات لا يعرف العاملين بهذه الأدوار التي من المفترض القيام بها وهو ما يشير إلى حالة الفوضى الإدارية في تلك المؤسسات.

\section{مفهوم الأدوار:}

عرف ليفي أن الدور هو بمثابة مركز متميز في نطاق بنيان اجتماعي معين، وعرف بارسونز أن الدور هو ما يقوم بفعله الفاعل الاجتماعي في علاقته مع الآخرين، وكما عرف ميريل أن الدور يعتبر نموذجا من السلوك المتوقع والمرتبط بموقع معين في مجتمع معين، وعرف أحمد عزت الدور هو نمط السلوك الذي تنتظره الجماعة وتتطلبه من فرد له مكز معين فيها وهو سلوك يميز الفرد عن غيره مُن يشغلون مراكز أخرى، وعرف بيدل أن مفهوم الدور يمثل تلك الممارسات السلوكية المميزة لواحد أو أكثر من الأشخاص في إطار معين(4). وعرف بيدل وتوماس (Biddle \& Thomas, 1966) الدور بأنه مجموعة من الصفات التي تحدد تصرفات الشخص في وظيفة معينة، ويخلص بعض الباحثين بأن الدور هو حجر الأساس في الأنظمة الاجتماعية وهو عبارة عن مجموعة من المتطلبات الذي يفرضها التنظيم على الموظف، كاتز وكاهن (Katz \& Kahn,1978)، 
وتعمل الأدوار كحدود بين الفرد الموظف وبين المنظمة، حيث تمثل الأدوار مجموعة من التوقعات من قبل الفرد والمنظمة ولذلك تخدم الأدوار على ربط الفرد بالمنظمة والعكس (Schuler Aldag, \& Brief, 1977).

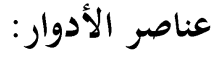

هناك من يقوم بتعريف الدور عبر تمييزه إلى عناصر هي (5):

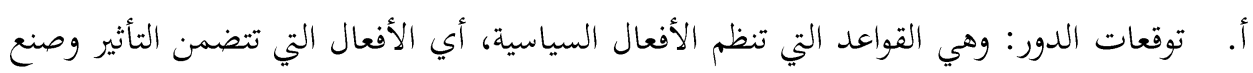

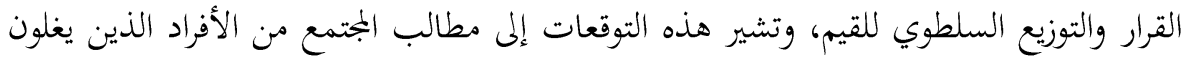
مناصب متشاهة. ب. توجهات الدور: وهي الأفكار الخاصة بالفرد شاغل الدور كالسلوك الذي يجب أن يسلكه في

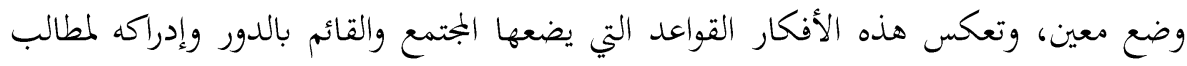

$$
\text { وتوقعات من حوله. }
$$

ت. سلوك الدور: وهو عبارة عن الأفعال التي يقوم هما الفرد الذي يغل منصبا معينا حيث يتم التركيز هنا على الفعل كما حدث لا كما يجب أن يكون.

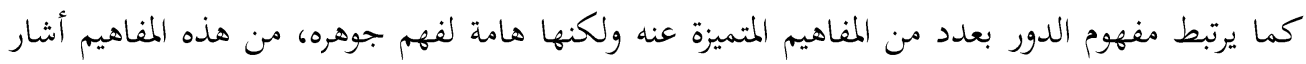

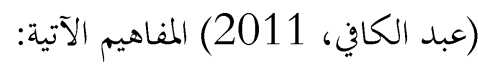

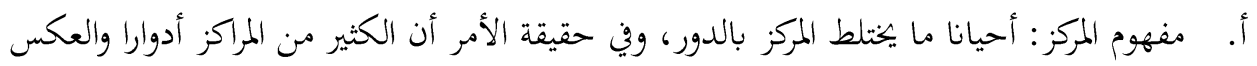
بالعكس ولكن المراكز تعتبر تصنيفات للكائنات الإنسانية بينما تعتبر الأدوار تصنيفات للسلوك.

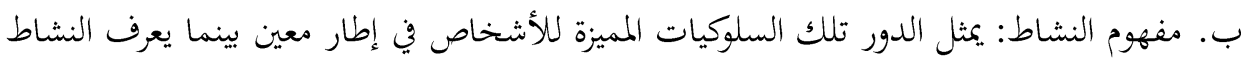

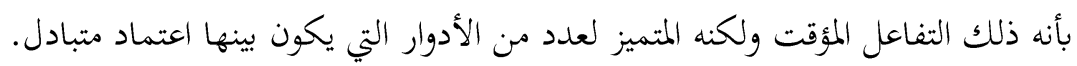

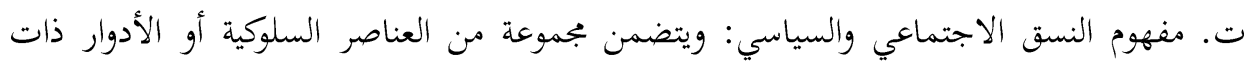

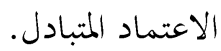

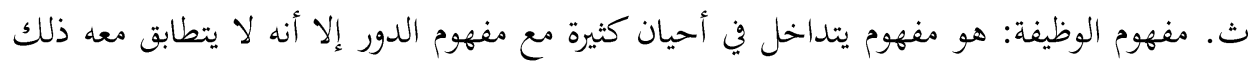
لأن الدور غير الوظيفة حيث يشمل الممارسة. وترى الدراسة أن الأدوار هي الصفات التي تحدد لي الفرد في المدارسة أداء عملة، حيث كيف يكون

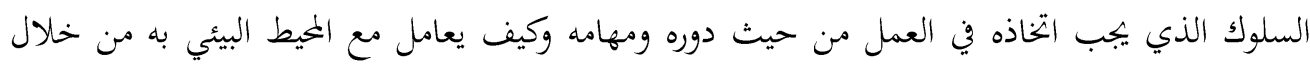




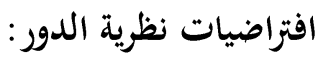

وتتبني نظرية الدور على خمس افتراضات أساسية، يوجد عليها اتفاق عام بين العلوم الاجتماعية المختلفة

الافتراض الأول: إن بعض أنماط السلوك تعد صفة ميزة لأداء الأفراد الذين يعملون داخل إطار معين.

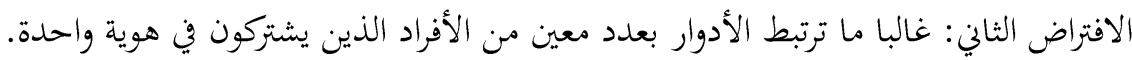

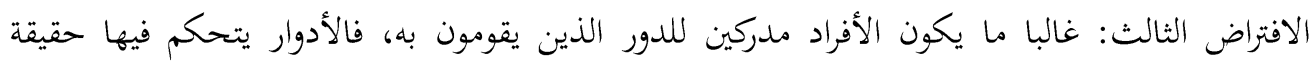
الإلدراك بها. الافتراض الرابع: تستمر الأدوار بسبب ما يترتب عليها من نتائج من ناحية، وبسبب ارتباطها بسياق نظم اجتماعية أكثر اتساعا من ناحية أخرى.

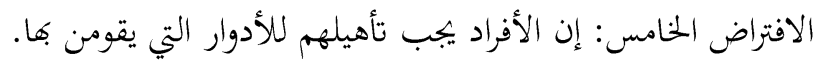

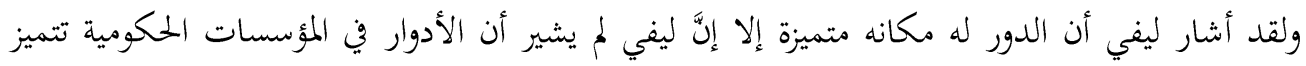

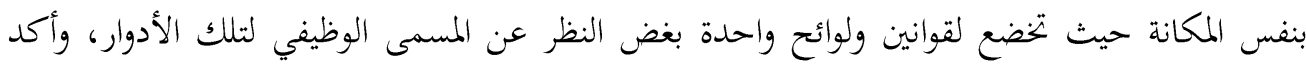

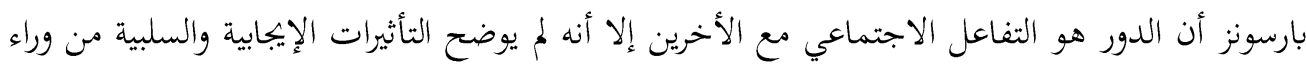

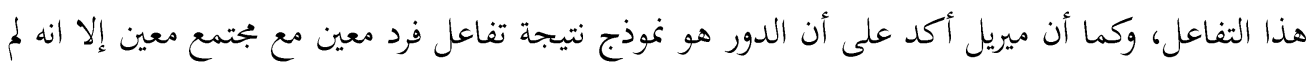

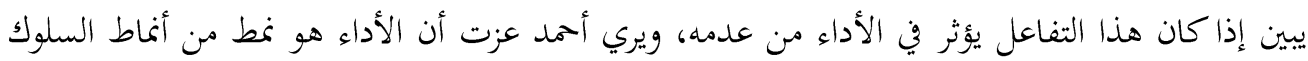

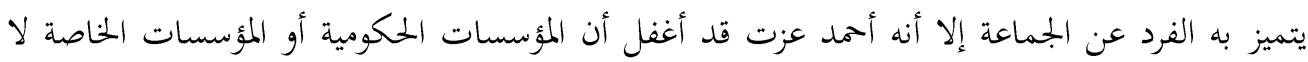
تعمل في الوقت الراهن على انتظار الأداء المتميز للعاملين بل إها تعمل على تميز الأداء حيث أهما تعمل إنهل

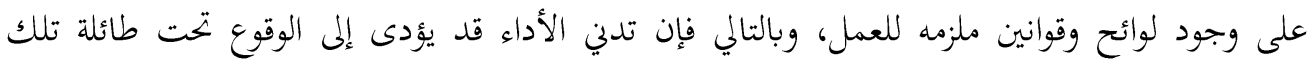
اللوائح والقوانين. وأشار عبد الكافي (2011) أن الأدوار هي ممارسات سلوكية تسعي إلى تمييز الفرد عن الجماعة إلا إلَّ عبد الكافي (2011) لم يوضح كيف يمكن ممارسة هذه السلوكيات في ظل مؤسسات لا تعترف بتمييز سلوك

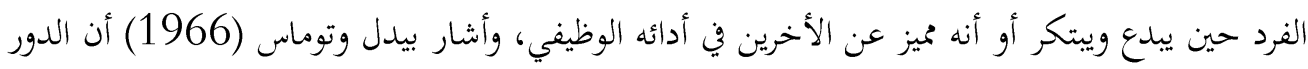
هي مجموعة من الصفات التي يمكن من خلالها تحديد تصرفات الفرد وحصرها في وظائف محدده إلا إلَّ

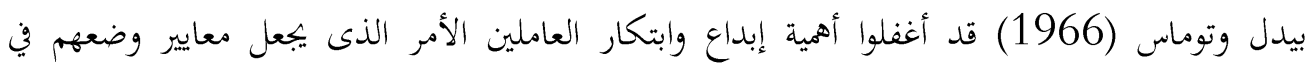
وظائف محدده غير دقيق علمياً، وأما كاتز وكاهن (1978) قد أكدوا أن الأدوار تعمل بمثابة الحد الفاصل الفرل 
بين الفرد والمؤسسة إلا أفم أغفلوا أنه من المفترض أن تعتمد المنظمة على الفرد ومؤهلاته وقدراته وكفاءته

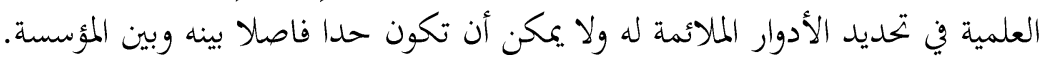
ولقد أوضح عبد الكاين (2011) أن مفهوم الأدوار يتميز بالعديد من المميزات من بينها التوقعات بالدور

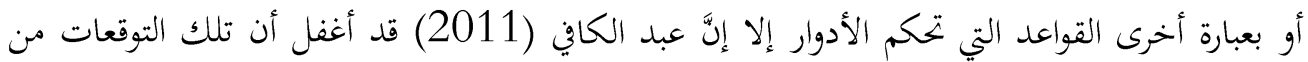
شاها تقوم بتوزيع السلطات والمهام بشكل عشوائي على العاملين بدون وجود أساس علمي يرتكز عليه،

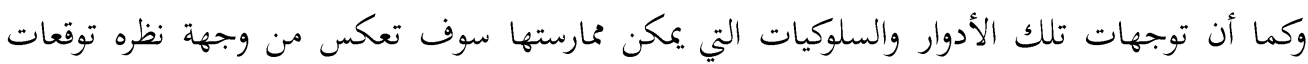
لمطالب من يقوم بالأدوار مستقبلا إلا إنَّ عبد الكافي (2011) أغفل أن سلوكيات الفرد وأفكاره الخاصة غير مطالب بها في العمل وخاصة إذا كان العمل في المؤسسات الحكومية عملا نمطيا دون إبداع، وبالتالي

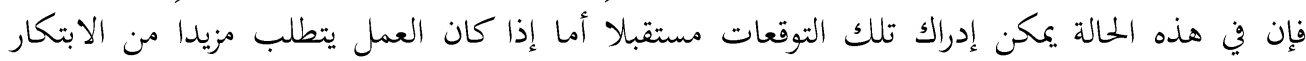
والإبداع فإنه يصعب التعرف على توجهات الأدوار خاصة إذا كان الموظف يجتهد بشده لإنجاز الأعمال في أقصر وقت منكن. ولقد ركز عبد الكافي (2011) على سلوكيات الأدوار وهي عبارة عن الأفعال التي يقوم بها الفرد الذي

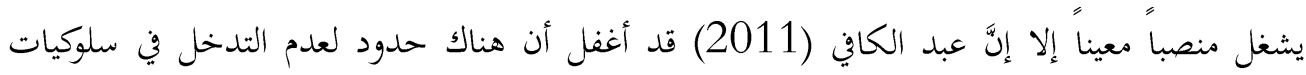
الأفراد أو من يمارسون أدوراً رفيعة مما قد يضعف من من ضرورة التركيز على سلوكيات من يمارسون أدورا رفيعة في المجتمع، وأوضح عبد الكافي (2011) أن مفهوم الأدوار يرتبط بالعديد من المفاهيم الأخرى من بينها

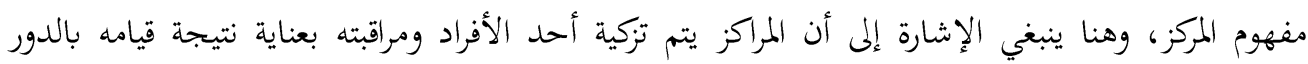

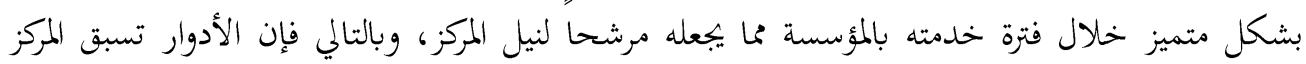
وليس العكس، كما أن عبد الكافي (2011) قد أكد على أن الأدوار تختلف عن عند السلوكيات المميزة

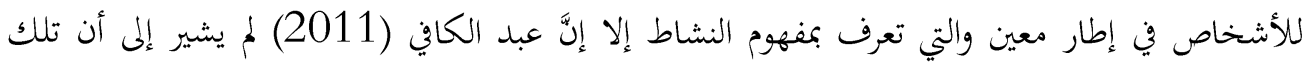

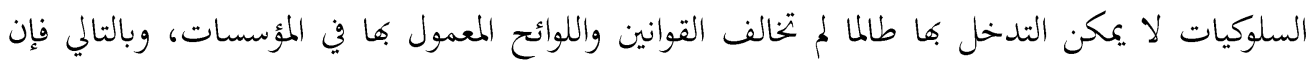
مفهوم الأدوار يختلف عن مفهوم النشاط الذى يعتمد على تلك السلوكيات بشكل كبير.

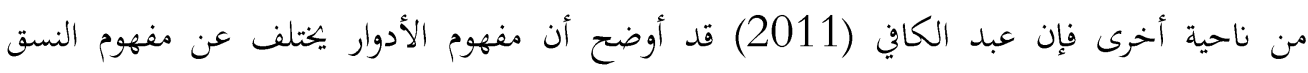
الاجتماعي والسياسي إلا إنَّ عبد الكافي (2011) لم يشير إلى أن كلا المفهومين يعتمد على بعضهم البعض حيث أن الأدوار تقع فيه المسئولية على موظف بعينه أما مفهوم النسق الاجتماعي والسياسي فهو يعتمد على تبادل الأدوار، ويرى عبد الكافي (2011) أن مفهوم الأدوار يختلف عن مفهوم الوظيفة حيث أن الوظيفة هي ممارسة الدور أما الأدوار هي وقوع مسئولية نشاط معين أو مهام معينه على موظف بعينه. 
ويرى عبد الكافي (2011) أن نظرية الدور تعتمد على فروض أساسية من بينها أن بعض أنماط السلوك

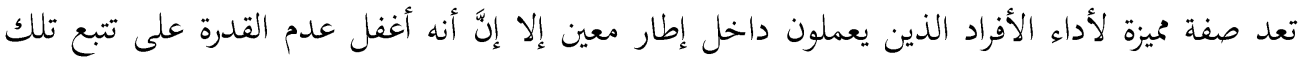

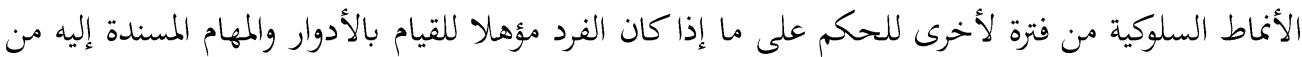

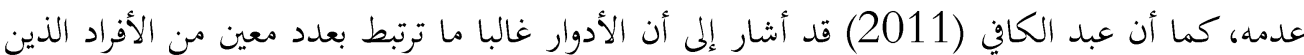

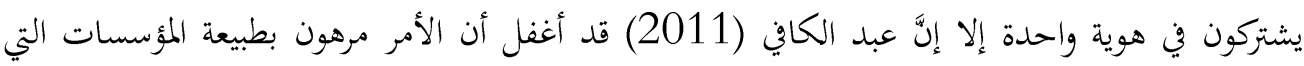

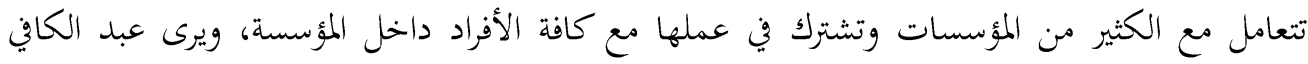

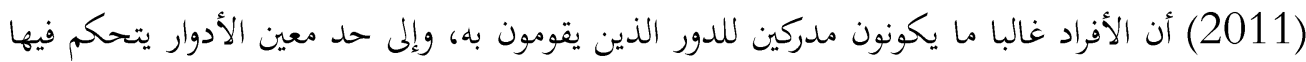

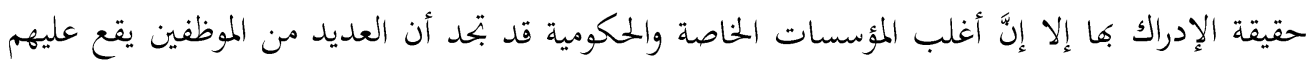
عبء أدوار معينة ويقومون بالجمع بين العديد من الأدوار.

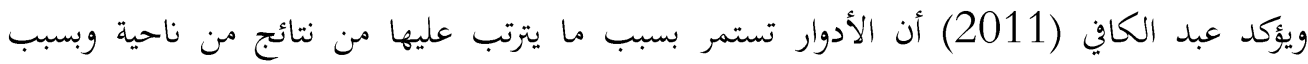

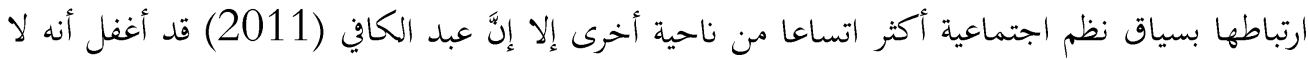
مككن ضبط معايير خاصة بالأدوار بسبب اختلاف النظم الاجتماعية وبسبب وجود نظم أخرى تتأثر بها

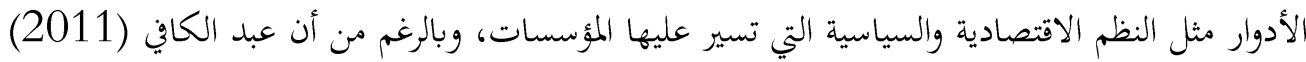

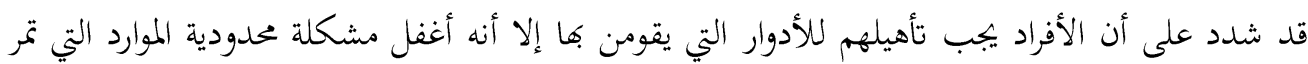

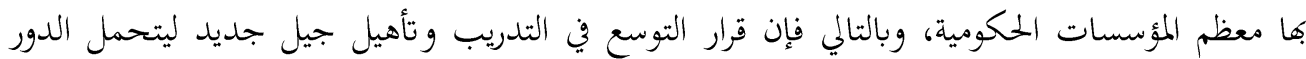
المنوط به يصعب تنفيذه بسبب قلة الموارد المالية.

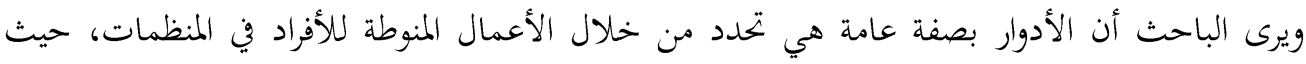

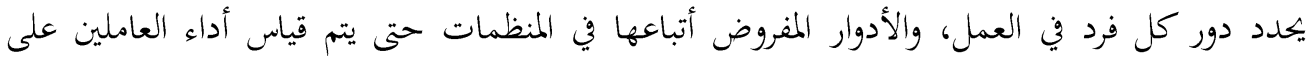
أدوارهم، وهكذا تكون الأدوار واضح للعاملين والمنظمة.

\section{المبحث الثالث: تحقيق الأهداف}

إن عملية تحقيق الأهداف تكون من خلال تغيير شيء من حال إلى حال أفضل، مع التعرف على سبب الفال الضعف ومحاولة الوصول إلى طرق معالجته، وعملية تحقيق الأهداف تحدد الأداء الجيد، وتقوم على تحفيزه صاحبه من خلال ترقية وتشجيعه، وتعتمد هذه العملية على بجموعة من الخطوات التي تبدأ بقياس الأداء

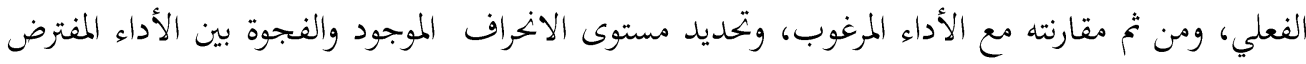

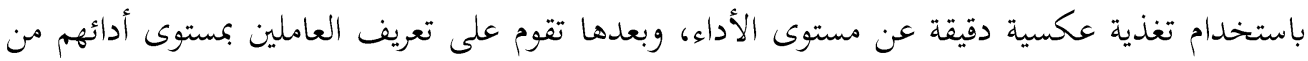


أجل إجراءات تصحيح لأي انحراف، والقضاء على الفجوة الموجودة باستخدام مدخلات خاصة لتحسين الأداء (7)

تقوم عملية تحقيق الأهداف على تحسين وتنمية قدرات الأفراد العاملين، من خلال التركيز على تطوير مهاراقم المهنية وتزويدهم بكل ما هو جيد وجديد في مجال عملهم، إن عملية تحقيق الأهداف الأداء هلا

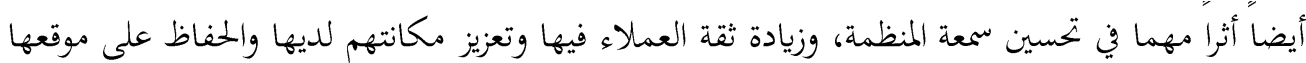

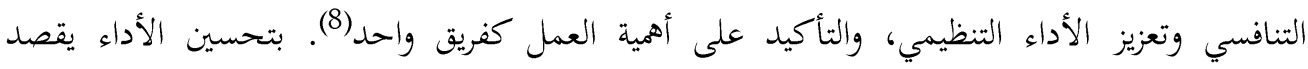
استخدام جميع الموارد المتاحة لتحسين المخرجات وإنتاجية العمليات، وتحقيق التكامل بين التكنولوجيا الصحيحة التي توظف رأس المال بالطريقة المثلى، ويتطلب تحسين الأداء توازن مجموعة من العناصر التي

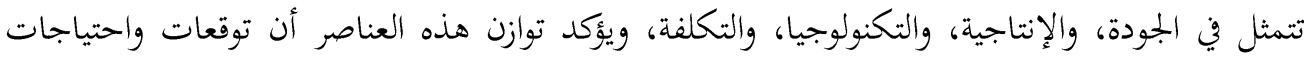
أصحاب المصلحة في المؤسسة قد أخذت بعين الاعتبار، ويطلق على هذا المنهج المتكامل إدارة التحسين (9) الشامل تتم إجراءات تحقيق الأهداف هي من خلال الخطوات الآتية(10):

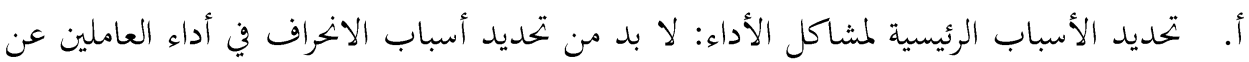

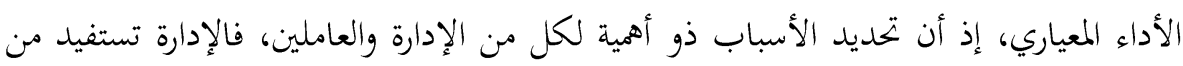

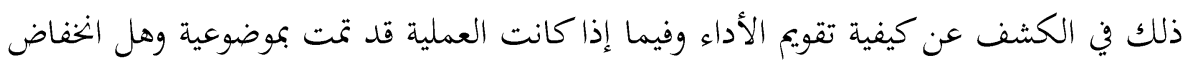
الأداء عائد للعاملين أو أن ندرة الموارد المتاحة لهم هي السبب الرئي الرئيسي. ب. تطوير خطة عمل للوصول إلى الحلول: تمثل خطة العمل اللازمة للتقليل من مشكلات الأداء ووضع الحلول لها التعاون بين الإدارة والعاملين من جهة والاستشاريين الاختصاصيين في مجال تطوير وتحسين الأداء. ت. الاتصالات المباشرة: إن الاتصالات بين المشرفين والعاملين ذات أهمية في تحسين الأداء، ولا بد من تحديد محتوى الاتصال وأسلوبه وأنماط الاتصال المناسبة. ويقسم (الخزامي، 1999) حسب رأي علماء الإدارة عناصر إدارة تحسين الأداء إلى ما يأيت:

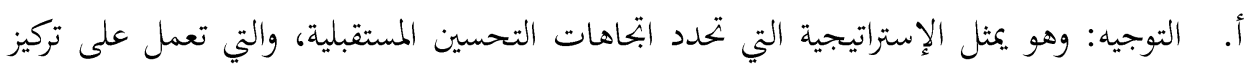
الطاقات وحشد الجهود لتحسين علاقات العمل الرئيسة في المؤسسة. ب. المفاهيم الأساسية: وهي تتميز بأهما تضع المؤسسة أمام منهجيات التحسين الأساسية التي تتكامل مع الأنشطة العادية لأداء الأعمال. 
ت. عمليات التسليم: وهي تركز على عمليات تحفيز صناعة المنتج أو الخدمة التي تجعل المؤسسة أكثر كفاءة وفعالية، وتزيد من قدرها على التكيف، وفي الوقت ذاته تخفض الوقت والجهد والتكلفة. ث. التأثير التنظيمي: وهو يختص بوضع المقاييس والهيكل التنظيمي للمؤسسة. ج. المكافآت والاعتراف بالفضل: ويختص هذا الجانب بنظام المكافآت والاعتراف بالفضل الذي يتضمن الحوافز المالية وغير المالية بهدف دعم أهمية المهام الأخرى داخل البناء الهرمي.

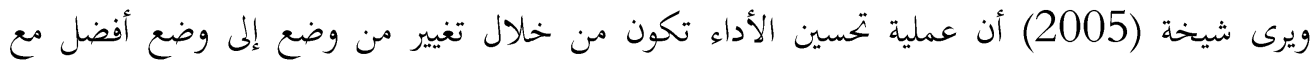

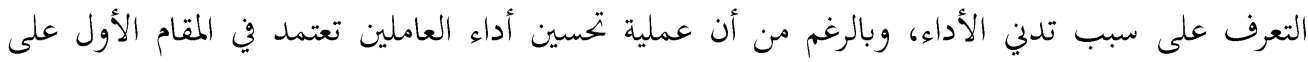
الخطوات الفعلية التي يمكن اتخاذ ها من أجل ضبط وتحسين الأداء إلا إلَّ شيخه (2005) أغفل ما قد إند يتعرض له العاملين من ردة فعل من وراء التعرف على تقاريرهم السلبية ما يشير إلى ضرورة وضع خطة عمل

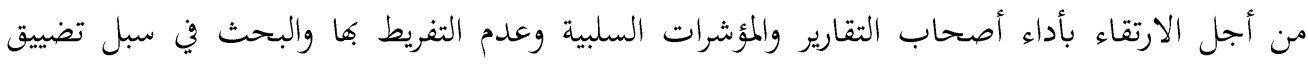

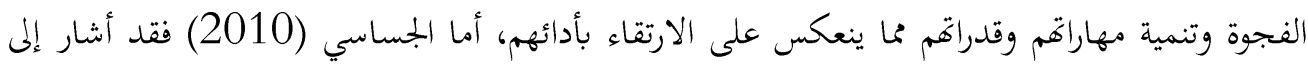

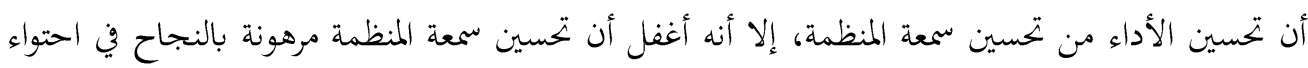
العاملين الذين صدرت بحقهم تقارير سلبية والتعرف على مصدر الخللل وسرعة معالجته. أما الخزامي (1999) فقد أشار إلى أن تحسين الأداء يقصد به استخدام جميع الموارد المتاحة لتحسين المخرجات، وتحقيق التكامل بين عناصر التكنولوجيا الصحيحة التي توظف رأس المال بالطريقة المثلى،

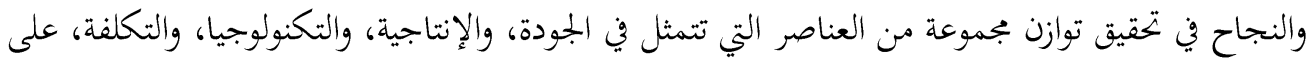
أن يؤكد توازن هذه العناصر أن توقعات واحتياجات أصحاب المصلحة في المؤسسة قد أخذت بعن بعين

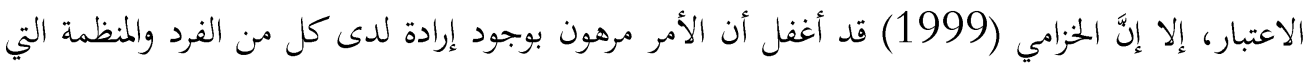

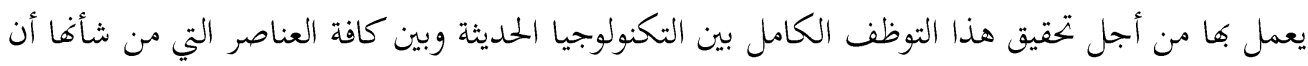
تحسين الجودة من خلال رفع مستوى الكفاءة والإنتاجية. وأشار عباس (2003) أن إجراءات تحسين مستوى الأداء يمكن أن يتم من خلال تحدين تحديد الأسباب الرئيسية لمشاكل الأداء، إلا إنَّ عباس (2003) قد أغفل أن المؤسسات الحكومية تحكمها لوائح وأن العبرة برضا المدير المباشر، وبالتالي فإنه لا يمكن أن تتم إجراءات تحسين الأداء بموضوعية، وكذلك فإِان عباس (2003)

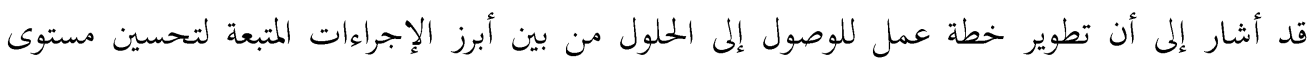

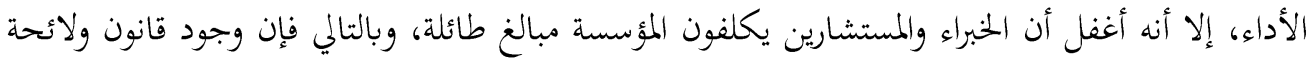


تقر بالخصم على العاملين دون النظر في المؤثرات التي يتعرض لها في عمله أفضل من أن تتكبد المؤسسة مبالغ طائله من استقطاب الخبراء والمستشارين. ويزكد الخزامي (1999) أن الاتصالات بين المشرفين والعاملين ذات أهمية في تحسين الأداء، إلا إنَّ الخزامي (1999) حيث أن الكثير من المؤسسات لا تسمح للكثير من المستويات الإدارية بالتواصل مع المشرفين

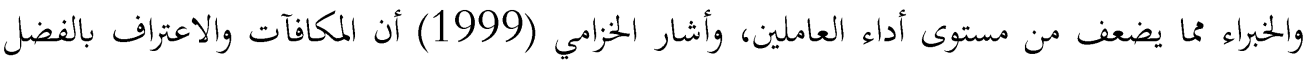

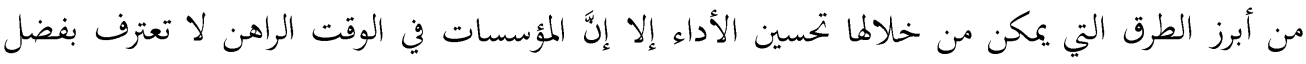

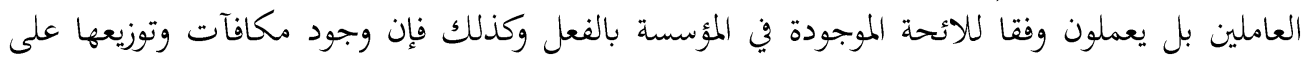
مستحقيها يعتبر تقدم نحو تحسين مستوى الأداء، ويرى الخزامي (1999) أن التأثير التنظيمي ووضع لئع مقاييس خاصة بالهيكل التنظيمي في المؤسسة والتركيز على عمليات تحفيز المنتجات أو الخدمة إلا التأثير التنظيمي يكون أضعف ما يكون في مؤسسات القطاع الخاص التي تعتمد على مرتكزات أخرى لدعم وضبط الأداء من خلال ربط الأجور بالإنتاجية. ويشير الخزامي (1999) أن عملية التوجيه وتعديل الاستراتيجيات يمكنها أن تحدد البحاهات التحسين المستقبلية إلا إنَّ الخزامي (1999) قد أغفل أهمية وضوح الرؤى والأهداف حتى يمكن تهني تعديل

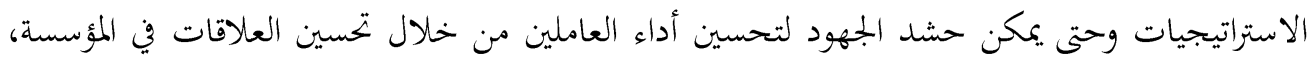
وأكد الخزامي (1999) أن يجب مراعاة المفاهيم الرئيسية التي تتكامل مع بعضها البعض من أجل ضين ضبط الأداء، إلا إنَّ الخزامي (1999) قد أغفل أن وضوح المنهجية سوف يسهم في تحسين الأداء بطريقة مباشرة إذا ما تم مراعاة أنشطة العمل الرئيسية.

الخاتمة:

أكدت الدراسة أبعاد كفاءة الأداء التنظيمي في تحقيق أهداف المنظمة، حين تتعرض المؤسسات للعديد من المؤثرات الخارجية والداخلية التي تؤثر على طبيعة ممارسات إدارة الموارد البشرية ودورها الرئيس في المنظمة. إذ إذهات لا يمكنها القيام بممارسة دور استشاري إلا في نطاق محدود وفق ما تسمح به اللوائح والقوانين في

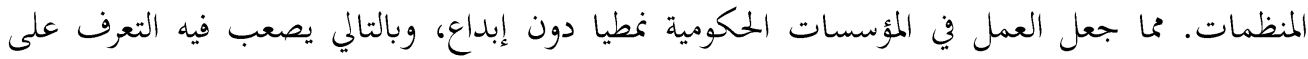

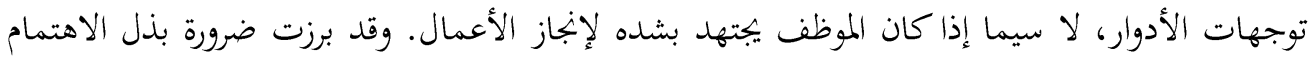

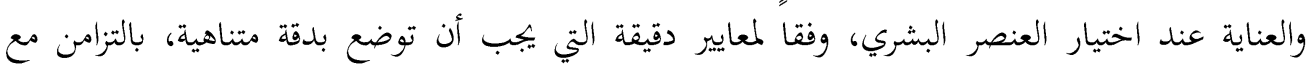

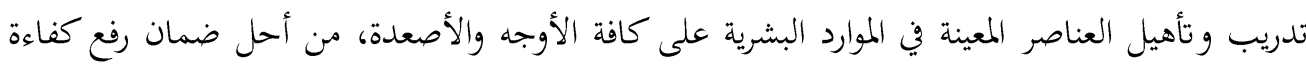
القيادات الإدارية في كافة المؤسسات العمانية، في إطار السعي إلى تطوير اللوائح والقوانين العاملة. 


\section{المصادر:}

1. المازوغي، أبو بكر. (2019). أثثر قيادة الموارد البشرية في تحسين الأداء التنظيمي: الثقافة التنظيمية كمتغير وسيط دراسة حالة شكة المدمات العامة فرع طرابلس، رسالة دكتوراة غير منشورة، كلية الإدارة جامعة شاة علم، ماليزيا. أبو سوار، أبو القاسم على حسن. (2019). أثر التخطيط الاستراتيجي على الأداء المؤسسي الثقافة التنظيمية كمتغير وسيط، دراسة تطبيقية على شركة .2

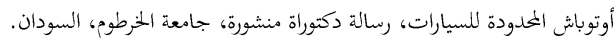

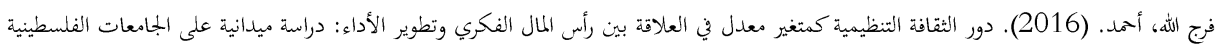

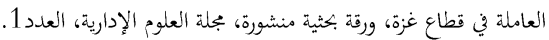

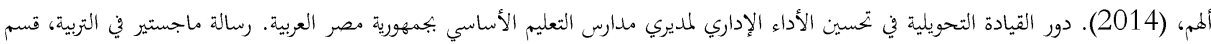

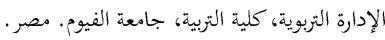
5.

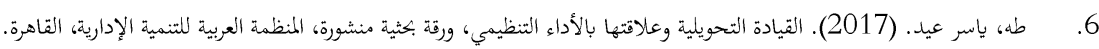

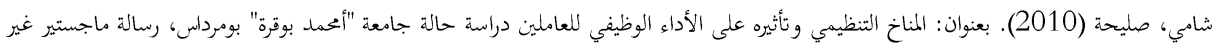
منشورة، جامعة "أبعمد بوقرة" بومرداس، الجزائر.

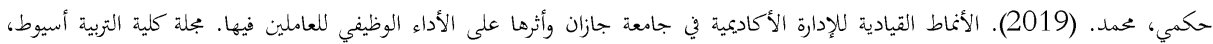

$$
\begin{aligned}
& \text { (1) عاشور، } 2010 . \\
& \text { (2) شاويش، } 2000 . \\
& \text { (3) تقرير خطة عمان، } 2020 \text { (2) } \\
& \text { (4) عبدالكافي، } 2011 \text { (3) عبدر عان، } \\
& \text { (5) عبدالكاني، } 2011 . \\
& \text { (6) عبد الكاني، } 2011 . \\
& \text { (7) أبو شيخة، } 2005 \text { (8) } \\
& \text { (8) الجساسي، } 2010 . \\
& \text { (9) الحزامي، } 1999 . \\
& \text { (10) عباس، } 2003 .
\end{aligned}
$$

